REAL-TIME INFORMATION SUPPORT FOR STRATEGIC SAFETY INSPECTION ON CONSTRUCTION SITES

Hao Zhang and *Seokho Chi

Queensland University of Technology

2 George Street

Brisbane, Australia 4001

Seoul National University

35-304 1 Gwanak-ro, Gwanak-ku,

Seoul, Korea 151-744

(*Corresponding author: shchi@snu.ac.kr) 


\title{
REAL-TIME INFORMATION SUPPORT FOR STRATEGIC SAFETY INSPECTION ON CONSTRUCTION SITES
}

\begin{abstract}
Site inspection is an important component of safety management system. In current practices, the inspectors evaluate the safety condition on a construction site with the assistance of a standardised checklist. However, the checklist emphasizes on evaluating the implementation of safety management system, but provides limited task-specific check items for assessing whether the individual construction tasks are conducted under safe condition and in a safe manner. To address this issue, the research presented in this paper aims to provide safety practitioners with comprehensive and taskspecific safety information to promote effective risk identification and facilitate strategic risk control during site inspection. Specifically, this research first builds a project-specific safety information database, which stores potential risks and control measures for each construction task. The research team then develops a mobile decision support tool to retrieve information from the database and support safer decision-making on site. The tool supports users in two ways: one is to provide daily risk checklists and risk control strategies to guide step-by-step inspection alongside the project schedule; the other is to let users input any safety-related keywords during the safety inspection process and the tool returns relevant safety information by applying text mining algorithms. It is ongoing research. This paper presents an overall research framework and discusses the progress in developing safety database and data retrieval concepts. The outcome of the project will help enhance safety management practices and reduce possible risky working conditions on a construction site.
\end{abstract}

\section{KEYWORDS}

Construction safety inspection, Safety information database, Risk identification, Decision support

\section{INTRODUCTION}

Site inspection is regarded as an important component of safety management system (Hinze, 1997; Hallowell, 2008). In the safety planning before work commences, potential risks are identified, and control measures selected (Chua \& Goh, 2004). As a way to ensure the safety plans are implemented, regular and random site inspection is needed (Workplace Health and Safety Queensland, 2013). During the inspection, checklists are used to remind inspectors of the items that verify on-site safety status (Albert \& Hallowell, 2012). However, in many cases, checklists are designed to evaluate the performance of safety management system (Jannadi \& Assaf, 1998; Teo \& Ling, 2006), so general items such as management policy are included; few checklists emphasize on providing risk information for a certain construction task (e.g. concrete pouring, roofing). Thus, there is a lack of tool to provide assistance in assessing whether tasks are conducted under safe condition and in a safe manner. In previous studies, the idea of automatic safety monitoring came out with the development of smart sensing technologies. Navon and Kolton (2006) developed a fall hazards monitoring model, which can detect any missing or incomplete guardrails by comparing the on-site guardrail condition with the planned one and then issue warnings when necessary. Chi and Caldas (2012) designed an automated warning mechanism against risky earthmoving conditions. In this study, 3D video cameras were used to track construction resources automatically and the research output promoted real-time safety assessment on construction sites. While these systems worked well during case studies, they focused more on the application of available technologies instead of thoroughly considering safety 
decision-making processes. In other words, safety rules defined in these systems were not clear enough to describe complicated and unpredictable construction environments. Human decisionmaking is still needed.

In other studies, researchers introduced database concepts and information retrieval technologies to collect and retrieve relevant information to support safety decision-making. Carter and Smith (2006) developed a web-based tool that helped engineers produce work method statements with higher level of hazard identification. Once the construction method was defined, the tool was able to inform users what hazards can be associated with expected tasks. Goh and Chua (2009) investigated a case-based reasoning approach that retrieved historical incident cases having similar case scenarios from their database and facilitated hazard identification processes. While these systems were designed to support safety planning more, rather than real-time site safety inspection, the information support methodology can be used for site inspection as well.

The emerging mobile computing technology provides an easy way to deliver useful information to the site and collect necessary data from there. Mobile computing technology has been applied in many aspects of construction management. In 1999, PDA (Palm personal digital assistant) was used on site to collect inspection data and then transfer it to PC database, which reduced the redundancy and time consuming problems of paper-based data collection (Navarrete, 1999). On the other direction, Lipman (2004) used mobile handheld computer to deliver and visualize 3D models of construction components in the field. More recently, Kim, Lim, \& Kim (2011) presented a locationbased construction site management system with two modules: the first module explained the location information of both construction activities and the resources (i.e., materials, workers) allocated to the activities, and the second module provided an easy way to share construction drawings among construction engineers. These studies proved the mobile device as an efficient information exchange platform, confirming its application feasibility for site safety inspection.

In this regard, this research aims to combine the database concept and mobile computing technology to provide on-site safety inspectors with comprehensive and easily accessible safety information via a mobile decision support tool. The tool supports users in two ways: one is to provide a daily risk checklist and risk control strategies to assist step-by-step safety inspection alongside the project schedule. The checklist lists the task-specific physical and operational risks on site (e.g. unguarded edge, uncovered hole) and the corresponding control measures. It differs from the current checklist, which includes many indirect factors, like management policy, and serves as a tool to assess the safety management system (Zhang \& Chan, 2011). In addition, the checklist shows all the potential risks existing on the same date, maybe contains risks from several concurrent tasks. Given the probability and severity of each risk, risks can be prioritized for efficient control. The other supporting way is to let users input any safety-related keywords during the safety inspection process and the tool will return relevant safety information. All the information is extracted from the predeveloped project-specific safety information database. The research procedure is illustrated in Figure 1.

\section{RESEARCH METHODS}

\section{Safety Information Database Development}

To develop an effective safety database and support efficient risk identification and control, the research team explored all potential construction risks and grouped them by construction tasks so that the information can be well organized and easily accessible. The research first investigates what are necessary tasks in a building construction project. The National Classification System (NATSPEC Construction Information Systems Limited, 2012) which indicates a typical project work breakdown structure is used as reference to identify individual task elements. This step sets up the structure of the database (\#1 in Figure 1). 
Then, the second step is risk identification (\#2 in Figure 1), which fills contents for the database. This step is performed based on literature review, document analyses and expert consultation. Safety standards, code of practice, and best practice manuals, which describe the detailed procedures required to complete works safely, are reviewed for identifying potential risks and control measures of each task. The control measure guides how to control risks by eliminating or minimising them. The research team noticed that some safety standards are classified by particular safety concerns (e.g., fall hazards, inhalation) rather than construction tasks (e.g., site preparation, footing construction), thus the team needs to consider general construction methods of each task to understand what activities are needed for the tasks and what equipment and materials are used, and match each task with related safety standards. For example, cast-in-place concrete will be used for concrete retaining wall construction, thus safety standards about formwork, concrete pumping and plant operation need to be reviewed to identify the potential risks in completing this task. At last, industry experts will be contacted to review and confirm the practicality of the identified risks in each task and their control measures.

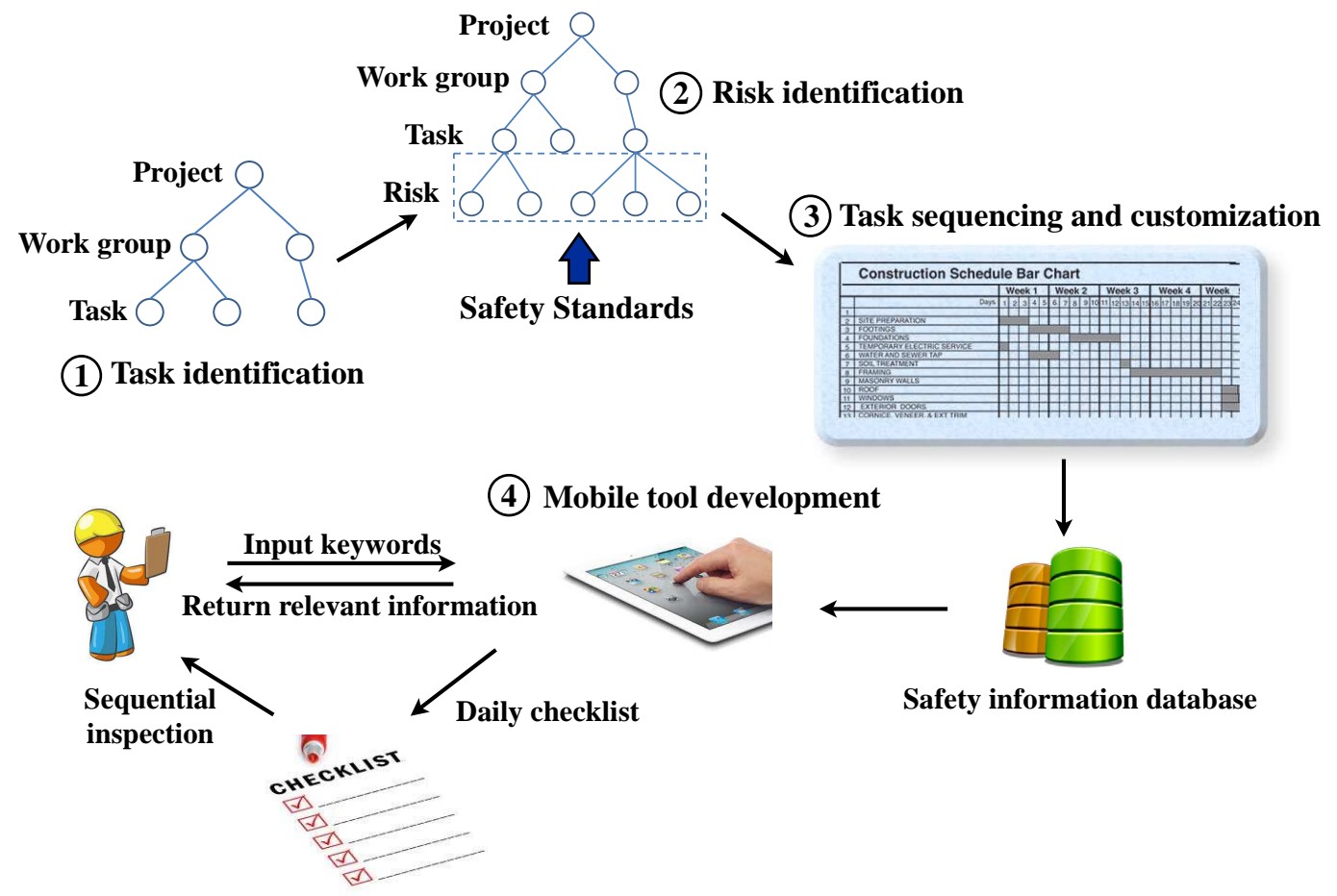

Figure 1 - Research procedure

The last step to build the database is to customize it for each individual project (\#3 in Figure 1). Specifically, identified tasks are modified and sequenced according to the construction schedule of a targeted project. This step makes the database more practical and enables step-by-step safety inspection alongside the project schedule. The ideal approach for this step is to develop an algorithm that can automatically identify what tasks are needed in this project according to the project schedule, and also extract the start and end time information of each task. Thus, people can know what tasks are being conducted on each day. However, in this preliminary stage, manual matching and information extraction would be applied for the feasibility testing purpose.

\section{Mobile Decision Support Tool Design}

The decision support tool is supposed to retrieve information from the database according to users' input. Considering the nature of outdoor work and tight work schedule, the information retrieval process should be simple, user friendly and not require much text inputs from the users. The 
retrieved information also should be easily understandable and ready to be used directly for the inspection.

To meet such needs, Apple iPad was chosen as the platform to develop the decision support tool due to its publicity and simplicity. The proposed tool will be built as an Application of iPad (\#4 in Figure 1). It contains two modules: the checklist module and the searching module, providing two different ways to retrieve information. The first module lets users choose the date on which they want to conduct safety inspection. The tool then generates a checklist, which includes all the potential risks in different tasks on that day. With this checklist, users will not miss any risks on site. Furthermore, when the user chooses one of the risks, its corresponding control measures will appear. Figure 2 shows an example of an interface of this module.

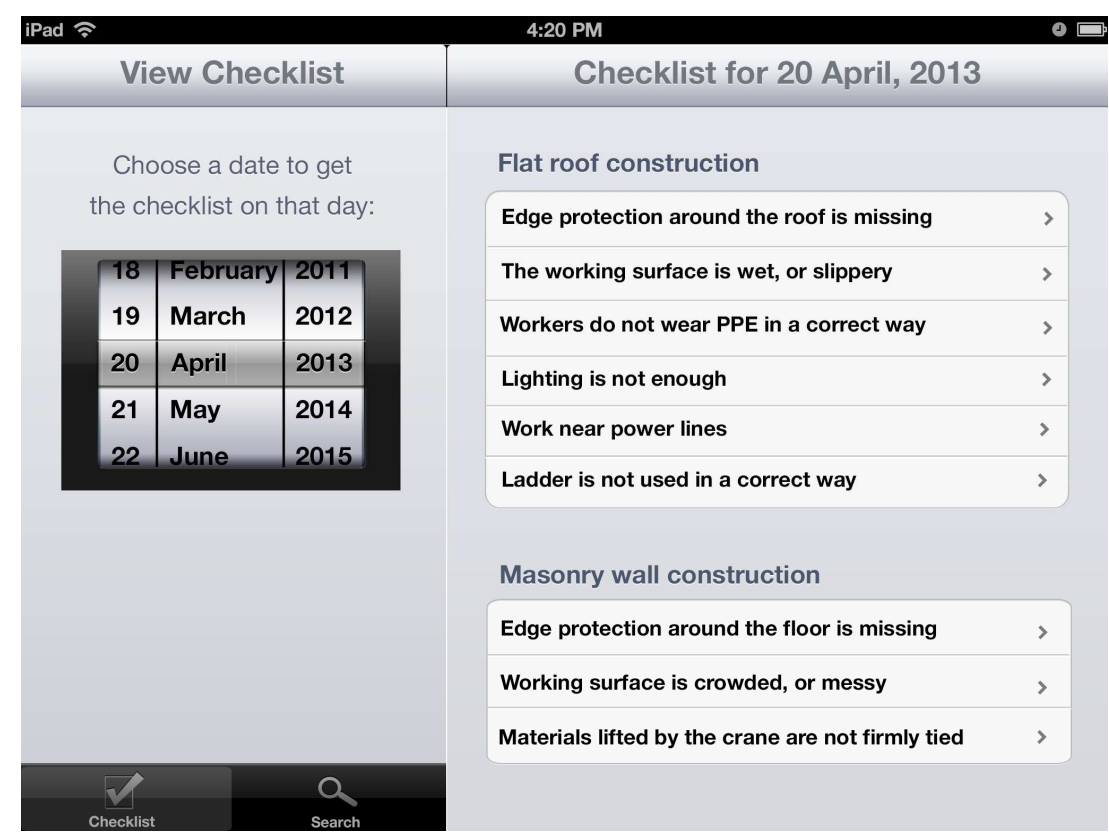

Figure 2 - Example of an interface of the mobile decision support tool

The searching module lets users input any safety-related keywords and it searches in the database and returns all the related information to support better risk identification and control. For example, if the user inputs the word "concrete", all tasks, risks, and control measures which include the word "concrete" will be returned with hyperlinks, which leads users to find further information.

\section{PRELIMINARY RESULTS AND DISCUSSIONS}

Until this stage, the database structure has been set up and risk information of a few construction tasks has been collected. Based on the National Classification System (NATSPEC Construction Information Systems Limited, 2012), a two-level breakdown structure of a typical building construction project was established as the database structure. The first level was called "work group". A project was divided into eight work groups: site, urban and open spaces, structure, enclosure, interior, finish, mechanical, hydraulic, and electrical. The second level was called "task". Table 1 shows tasks in each work group. In total, 33 tasks were identified for the eight work groups.

Table 1 - Project work breakdown structure

\begin{tabular}{ll}
\hline Work group & Task \\
\hline Site, urban and open spaces & Site clearing \\
& Excavation and backfilling \\
& Works in excavation \\
\hline
\end{tabular}




\begin{tabular}{ll}
\hline & Retaining wall construction \\
& Landscaping \\
& Road works \\
& Concrete footings construction \\
Cast-in-place concrete structure construction & Precast and tilt-up concrete installation \\
& Masonry structure construction \\
& Steel structure construction \\
& Timber structure construction \\
& Flat roof construction \\
Sloped roof construction \\
Enclosure & Curtain walls, planks, sheets construction \\
& Masonry walls construction \\
& Doors and windows installation \\
& Linings construction \\
& Partitions construction \\
Interior & Ceilings construction \\
& Access floors construction \\
& Fixtures construction \\
& Furniture and fixtures setting \\
& Column, beam, slab and wall painting \\
& Floor surfacing, tiling and waterproofing \\
Finish & External wall insulation and painting \\
& Ductwork and components construction \\
Mechanical & Piping \\
Hydraulic & Hydraulic systems installation \\
& Fire systems installation \\
Electrical & Power systems installation \\
& Electrical equipment installation \\
& Lighting system installation \\
\hline & \\
\hline
\end{tabular}

Safety standards in Queensland, Australia were then reviewed to identify the potential tasks and control measures for each of the above tasks. At this stage, only a few tasks were investigated as a pilot study. The referred safety standards included Work Health and Safety Regulation 2011 (Workplace Health and Safety Queensland, 2011c) and 13 construction-related Code of Practice issued by Workplace Health and Safety Queensland (WHSQ). To determine which standards should be referred for each task, the authors examined the construction methods (e.g., activities, equipment, and materials involved) for the tasks through consulting industrial practitioners, reviewing construction manuals, and watching construction video instructions. For example, for site clearing tasks, the required activities include equipment operations and manual works; and the involved equipment might include bulldozers, excavators and trucks. Thus, the related standards were Plant Code of Practice (Workplace Health and Safety Queensland, 2005), Hazardous Manual Tasks Code of Practice (Workplace Health and Safety Queensland, 2011a) and Managing the Work Environment and Facilities Code of Practice (Workplace Health and Safety Queensland, 2011b). By reviewing these standards, a list of risks in this task was generated as well as the corresponding control measures. Table 2 shows the risk information for the site clearing task. Such information identification process has been applied for other three tasks: excavation and backfilling, work in excavation, and retaining wall construction so far. In future study, other tasks will be investigated and a real project schedule will be incorporated to sequence and modify the tasks.

Table 2 - Potential risks and control measures of site clearing task

\begin{tabular}{lll}
\hline Hazard sources & Risk & Control measures \\
\hline $\begin{array}{l}\text { Site entry and } \\
\text { exit }\end{array}$ & Worker slipping & $\begin{array}{l}\text { Make the site entry and exit route slip- } \\
\text { resistant }\end{array}$ \\
\hline
\end{tabular}




\begin{tabular}{|c|c|c|}
\hline & & $\begin{array}{l}\text { Aisles and walkways should be at least } \\
600 \mathrm{~mm} \text { wide and kept free of furniture or } \\
\text { other obstructions at all times }\end{array}$ \\
\hline & $\begin{array}{l}\text { Collision between mobile } \\
\text { equipment and pedestrians }\end{array}$ & $\begin{array}{l}\text { Mark route boundaries by a permanent line } \\
\text { of white, yellow or other contrasting colour } \\
\text { at least } 50 \mathrm{~mm} \text { wide or by glowing markers }\end{array}$ \\
\hline & & $\begin{array}{l}\text { Separate the entries and exits for mobile } \\
\text { equipment and pedestrians }\end{array}$ \\
\hline \multirow[t]{2}{*}{ Working surface } & Worker tripping & Keep the walkways clear of obstructions \\
\hline & & Remove wastes regularly \\
\hline $\begin{array}{l}\text { Work near } \\
\text { services }\end{array}$ & $\begin{array}{l}\text { Underground essential } \\
\text { services broken }\end{array}$ & $\begin{array}{l}\text { Get the information of underground essential } \\
\text { services before commencing work }\end{array}$ \\
\hline \multirow[t]{3}{*}{$\begin{array}{l}\text { Equipment } \\
\text { operation }\end{array}$} & Falling objects & $\begin{array}{l}\text { Ensure the equipment use comply with } \\
\text { design }\end{array}$ \\
\hline & Equipment failure & $\begin{array}{l}\text { Ensure the operation comply with the correct } \\
\text { procedure }\end{array}$ \\
\hline & $\begin{array}{l}\text { Collision between } \\
\text { equipment or between } \\
\text { equipment and worker }\end{array}$ & $\begin{array}{l}\text { Ensure the driving speed of mobile } \\
\text { equipment consistent with site speed } \\
\text { restrictions }\end{array}$ \\
\hline $\begin{array}{l}\text { Personal } \\
\text { protection } \\
\text { equipment (PPE) }\end{array}$ & Lack of protection & $\begin{array}{l}\text { Ensure every worker on site is using PPE } \\
\text { and in a correct way }\end{array}$ \\
\hline \multirow[t]{3}{*}{$\begin{array}{l}\text { Worker exposure } \\
\text { to vehicular } \\
\text { traffic }\end{array}$} & $\begin{array}{l}\text { Collision between } \\
\text { equipment and worker }\end{array}$ & $\begin{array}{l}\text { Install warning device such as a reversing } \\
\text { alarm and/or flashing amber light on the } \\
\text { equipment }\end{array}$ \\
\hline & & $\begin{array}{l}\text { Appoint a spotter to direct and observe both } \\
\text { vehicles and personnel movement }\end{array}$ \\
\hline & & $\begin{array}{l}\text { Provide safety signs and/or guarding around } \\
\text { dangerous areas }\end{array}$ \\
\hline Lighting & Poor lighting condition & $\begin{array}{l}\text { Provide additional lighting, such as a lamp } \\
\text { on a movable arm; change the position of } \\
\text { existing lights; increase the number of lights; } \\
\text { change the type of lighting used }\end{array}$ \\
\hline
\end{tabular}

\section{CONCLUSIONS}

The objective of this research is to provide real-time information support for safety inspectors to conduct better risk identification and control on construction sites. This paper presented the preliminary research framework for this study. This research contains two main components: safety information database development and mobile decision support tool development. One component prepares information and the other delivers it. For building the database, 33 tasks were identified 
based on National Classification System by NATSPEC and potential risks and control measures for each task have been or are being collected through reviewing the safety standards issued by Workplace Health and Safety Queensland (WHSQ). The identified tasks are to be modified and sequenced according to project-specific schedule, which makes the database closer to real project conditions. The mobile decision support tool is also currently being developed on Apple iPad platform.

The future research will enrich the contents of database and complete developing the mobile tool. Furthermore, more advanced functions such as recording inspection results, generating reports, and providing prioritized risk control strategies can be developed. The outcome of this research can make site safety inspection processes easier and more accurate, and thus improve the performance of site safety inspection and reduce possible risky working conditions on a construction site.

\section{REFERENCES}

Albert, A., \& Hallowell, M. R. (2012). Hazard Recognition Methods in the Construction Industry. Paper presented at the Construction Research Congress 2012@ sConstruction Challenges in a Flat World.

Carter, G., \& Smith, S. (2006). Safety hazard identification on construction projects. Journal of Construction Engineering and Management, 132(2), 197-205. doi:10.1061/(ASCE)07339364(2006)132:2(197)

Chi, S., \& Caldas, C. (2012). Image-based safety assessment: Automated spatial safety risk identification of earthmoving and surface mining activities. Journal of Construction Engineering and Management, 138(3), 341-351. doi:10.1061/(ASCE)CO.1943-7862.0000438

Chua, D. K. H. \& Goh, Y. M. (2004). Incident Causation Model for Improving Feedback of Safety Knowledge. Journal of Construction Engineering and Management, 130(4), 542-551. doi: 10.1061/(ASCE)0733-9364(2004)130:4(542)

Goh, Y. M., \& Chua, D. K. H. (2009). Case-based reasoning for construction hazard identification: Case representation and retrieval. Journal of Construction Engineering and Management, 135(11), 1181-1189. doi:10.1061/(ASCE)CO.1943-7862.0000093

Hallowell, M. R. (2008). A formal model for construction safety and health risk management. (Doctoral dissertation). ProQuest Dissertations and Theses. Retrieved from http://search.proquest.com/docview/230670029?accountid=13380. (230670029).

Hinze, J. (1997). Construction safety. Upper Saddle River, NJ: Prentice-Hall.

Jannadi, M. O., \& Assaf, S. (1998). Safety assessment in the built environment of Saudi Arabia. Safety Science, 29(1),15-24. doi: 10.1016/S0925-7535(98)00018-6

Kim, C., Lim, H., \& Kim, H. (2011). Mobile computing platform for construction site management. Paper presented at the 2011 International Symposium on Automation and Robotics in Construction (ISARC), Seoul, Korea. URL: http://www.iaarc.org/publications/fulltext/S332.pdf

Lipman, R. R. (2004). Mobile 3D visualization for steel structures. Automation in Construction, 13(1), 119-125. doi:10.1016/j.autcon.2003.08.008

NATSPEC Construction Information Systems Limited. (2012). National Classification System. Retrieved from http://www.natspec.com.au/Products_Services/listallworksection.asp 
Navarrete, G. (1999). In the palm of your hand: Digital assistants aid in data collection. Journal of Management in Engineering, 15(4), 43-45. doi:10.1061/(ASCE)0742-597X(1999)15:4(43)

Navon, R., \& Kolton, O. (2006). Model for automated monitoring of fall hazards in building construction. Journal of Construction Engineering and Management, 132(7), 733-740. doi:10.1061/(ASCE)0733-9364(2006)132:7(733)

Teo, E. A. L., \& Ling, F. Y. Y. (2006). Developing a model to measure the effectiveness of safety management systems of construction sites. Building and Environment, 41(11), 1584-1592. doi: 10.1016/j.buildenv.2005.06.005

Workplace Health and Safety Queensland, Department of Justice and Attorney- General (2005). Plant Code of Practice. Retrieved from http://www.deir.qld.gov.au/workplace/resources/pdfs/plantcop-2005.pdf

Workplace Health and Safety Queensland, Department of Justice and Attorney- General (2011a). Hazardous Manual Tasks Code of Practice. Retrieved from http://www.deir.qld.gov.au/workplace/resources/pdfs/hazardous-manual-tasks-cop-2011.pdf

Workplace Health and Safety Queensland, Department of Justice and Attorney- General (2011b). Managing the Work Environment and Facilities Code of Practice. Retrieved from http://www.deir.qld.gov.au/workplace/resources/pdfs/work-environment-facilities-cop2011.pdf

Workplace Health and Safety Queensland, Department of Justice and Attorney- General (2011c). Work Health and Safety Regulation 2011. Retrieved from http://www.legislation.qld.gov.au/LEGISLTN/SLS/2011/11SL240.pdf

Workplace Health and Safety Queensland, Department of Justice and Attorney- General (2013). Safe work method statements [Online]. Available: http://www.deir.qld.gov.au/workplace/industry/construction/documentation/safe-workmethod-statements/index.htm.

Zhang, J., \& Chan, W. T. (2011). Developing a construction safety management system. Modeling Risk Management in Sustainable Construction (pp. 139-144): Springer. 